\title{
Development of Micro-magnetic Scale with Electroplating of Magnetism
}

Y. Sampei ${ }^{* * * *}$, H. Anzai*, Y. Itoh*, O. Maeda ${ }^{* *}$, H. Nakamura ${ }^{* *}$, S. Osanai $^{* *}$, K. Yamaguchi ${ }^{* * *}$, and O. Nittono ${ }^{* * *}$

*Fukushima Technology Centre, 1-12 Machiikedai, Koriyama 963-0215, Japan

${ }^{* *}$ Nikkoshi Co.,Ltd., 39-11 Abura-kubo, Sekibe, Shirakawa, Fukushima,961-0021, Japan

${ }^{* * *}$ Faculity of Symbiotic Systems Science, Fukushima Univ., 1 Kanayagawa, Fukushima 960-1296, Japan

A magnetic encoder is an element that detects the moved distance, speed, and rotation angle by sensing magnetism. This has been detected by reading the scale of the magnetic pattern with magnetic sensors. Therefore, it is possible to use these in severe situations such as in liquid and under dust. The magnetic scale of a magnetic encoder is obtained by machining a magnetic substance or by injection molding a plastic magnet. However, it is difficult to obtain the pitch on a detailed scale in the machining. Moreover, a plastic magnet is vulnerable to radiation. We aimed to develop a magnetic scale that was resistant to high temperature and radiation. We combined photolithography and electroplating to form an under 200-micro-meter micro-indentation pattern for the magnetic substance metal and used it as a scale.

Key Words: magnetic encoder, magnetic scale, photolithography, radiation resistance, micro pattern, electroplating

\section{磁性体の微細めっきによるマイクロ磁気スケールの開発

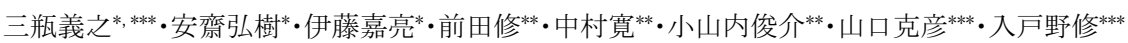 \\ *福島県ハイテクプラザ, 福島県郡山市待池台1-12( テ963-0215) \\ **ニッコーシ(森), 福島県白河市関辺字油久保39-11 (厂961-0021) \\ ***福島大学共生システム理工学類, 福島県福島市金谷川1 (テ960-1296)}

\section{1. はじめに}

磁気エンコーダーは, 磁気スケールを磁気センサーで読み 取ることにより, 移動距離や速度, 回転角度などを検出する素 子である. その信号検出には, 硬磁性体に着磁された磁気記 録をスケールとしてそれを読み取る方式と, 軟磁性体金属の凹 凸パターンをスケールとし, 外部磁場による磁化の差を検出す る方式の二種類が一般的に用いられている1).

磁気エンコーダーは液中や塵埃中, 強い光の下など光学式 エンコーダーが使用できない過酷な環境で使用される例が多 く, 放射線医療機器の内部制御などに高温下・放射線下で使 用可能な高分解能の磁気スケールが強く求められている.

しかし, 磁気記録を用いた方式では, 微細な磁気記録を検 出する為には記録媒体と検出部とのクリアランスを狭める必要 があり, 長期使用での信頼性が低下するという問題がある.

また熱や外部磁場による磁気記録の劣化や, 熱や放射線に よるプラスチックマグネットの劣化といった問題もあり, このよう な環境で使用することは難しかった2) 3).

軟磁性体金属の凹凸パターンを用いる方式では, MRセン サーを用いることでクリアランスを確保でき, 金属素材であるこ とから高温や放射線に対する耐久性も期待できるが, 機械加 工の際の工具径の限界や加工時間の問題からパターンピッチ が0.5 mm以下の磁気スケールを作成することは難しかった.

近年, X線リソグラフィーと電鋳技術を用いてnmオーダーの サイズのニッケル構造体を形成する技術が開発され, X線に代 わり紫外線リソグラフィーを用いた手法でも $\mu \mathrm{m}$ 以下のサイズ のニッケル構造体を形成する事が可能となっている4) 5).

この技術により形成された軟磁性体金属の微細構造をMR センサーにより非接触で検出できれば高分解能かつ耐高温・ 耐放射線の磁気スケールとして使用できる可能性がある.

本研究では, 高分解能かつ耐熱・耐放射線性の高い磁気ス
ケールの可能性について, 紫外線フォトリソグラフィーと電気め つきの組み合わせにより軟磁性体金属の微細構造を形成し, MRセンサーとバイアス磁石の組み合わせにより非接触で検出 することを試みた。

\section{2. 磁性体めっきと磁気特性の測定}

実験ではNiめっき, Fe-Ni合金めつきおよびFe-Co合金めっ きの電気めっきにより磁性体の皮膜を形成することを試みた。 $\mathrm{Ni}$ めっにはスルファミン酸ニッケル浴 $\left.{ }^{6}\right), \mathrm{Fe}-\mathrm{Ni}$ 合金めっきに は硫酸ニッケルー塩化ニッケルー第一鉄からなるめつき浴7), $\mathrm{Fe}-\mathrm{Co}$ 合金めっきは硫酸第一鉄一硫酸コバルトからなるめっき 浴8)を用いた. 基板には $\square 5 \mathrm{~mm} \times 0.5 \mathrm{mmt}$ の銅板, 浴温度 $50{ }^{\circ} \mathrm{C}$, 電流密度は $2 \mathrm{~A} / \mathrm{dm}^{2}$ で定電流制御によりめっきを行っ た. 析出しためっき皮膜は蛍光X線分析により元素分析を行っ た. その結果, スルファミン酸ニッケル浴からは純Niめっき, $\mathrm{Fe}-\mathrm{Ni}$ 合金めっき浴からはFe:Ni=2:8, $\mathrm{Fe}-\mathrm{Co}$ 合金めっき浴か らはFe: $\mathrm{Co}=4: 6$ の比率のめっきが析出していることが確認でき た. めっき皮膜の磁気特性については, 振動試料型磁力計に より測定を行った. 得られたヒステリシスカーブをFig.1に示す.

Fig.1の結果より, 今回作製したいずれの素材のめつき皮膜 も磁性を持っており，特にFe- $\mathrm{Ni}$ 合金めっきが軟磁性体として 良好な性能を有していることが確認できた。

この Fe-Ni合金めっき, およびFe-Co合金めっきについて, 真 空中で熱処理を行い, X線回折によりめっきの結晶性の評価を 行った. $\mathrm{Fe}-\mathrm{Ni}$ 合金めっきは $600{ }^{\circ} \mathrm{C}, \mathrm{Fe}-\mathrm{Co}$ 合金めっきは $700{ }^{\circ} \mathrm{C}$ と1000 ${ }^{\circ} \mathrm{C}$ で熱処理を行った. Fig. 2 に Fe-Ni合金めっ き, Fig.3にFe-Co合金めっきのX線回折測定結果を示す.

Fig.2およびFig.3より, $\mathrm{Fe}-\mathrm{Ni}$ 合金, $\mathrm{Fe}-\mathrm{Co}$ 合金のいずれもめ っき直後は結晶性が低いが, $\mathrm{Fe}-\mathrm{Ni}$ 合金は600 ${ }^{\circ} \mathrm{C}, \mathrm{Fe}-\mathrm{Co}$ 合

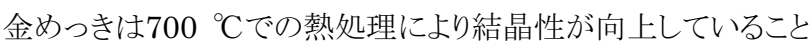



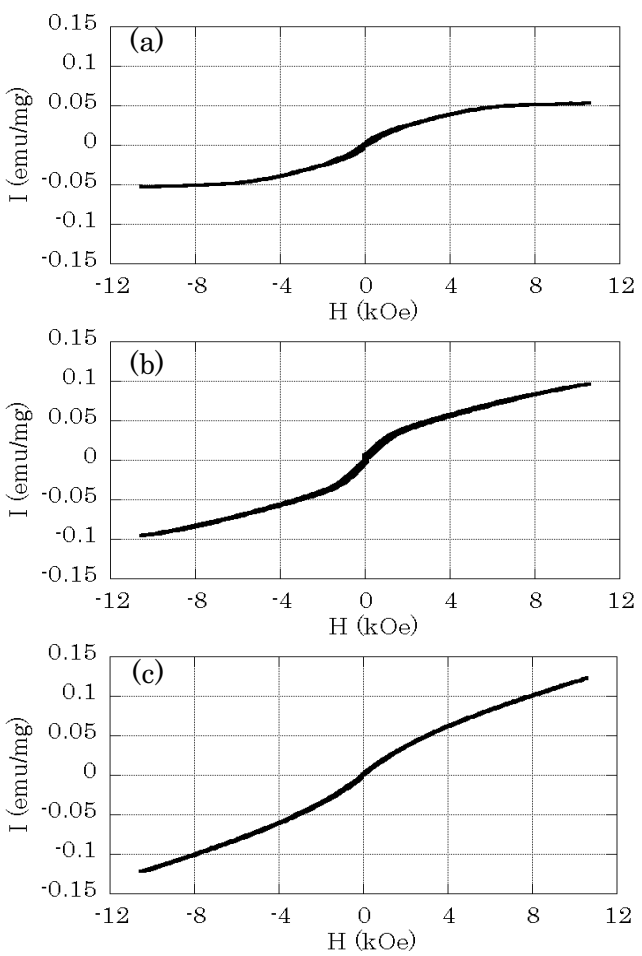

Fig. 1 Hysteresis curves for plating (a) $\mathrm{Ni}$, (b) $\mathrm{Fe}-\mathrm{Ni}$, and (c) $\mathrm{Fe}-\mathrm{Co}$
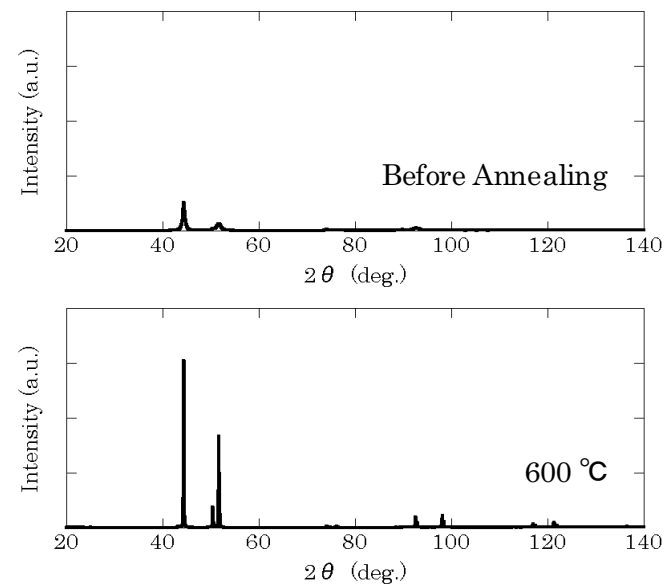

Fig. 2 XRD patterns of $\mathrm{Fe}-\mathrm{Ni}$ plating before and after annealing at $600{ }^{\circ} \mathrm{C}$.

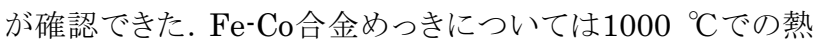
処理では逆に結晶性が低下していることが確認できた.

熱処理前後における磁気特性の変化について試料振動型 磁力計にて測定を行った. Fig.4に熱処理前後での保磁力と 飽和磁化について未処理品を基準とした相対值で示す.

Fig.4よりFe-Ni合金めっきは保磁力, 飽和磁化ともに大きな 変化が見られなかったが, 後述する磁気センサによる評価では 信号強度の著しい増加が見られた．Fe-Co合金めっきでは $700{ }^{\circ} \mathrm{C}$ での熱処理により保磁力の増加が見られた.これは, 熱処理による結晶性の向上に起因しているものと考えられる.
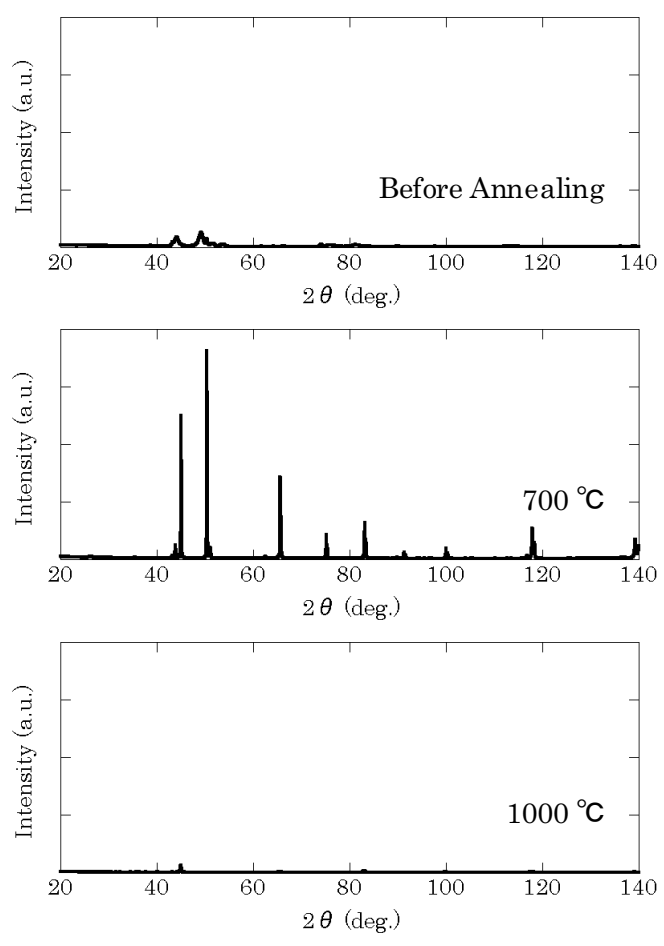

Fig. 3 XRD patterns of Fe-Co plating befor and after annealing at $700{ }^{\circ} \mathrm{C}$ and $1000{ }^{\circ} \mathrm{C}$.
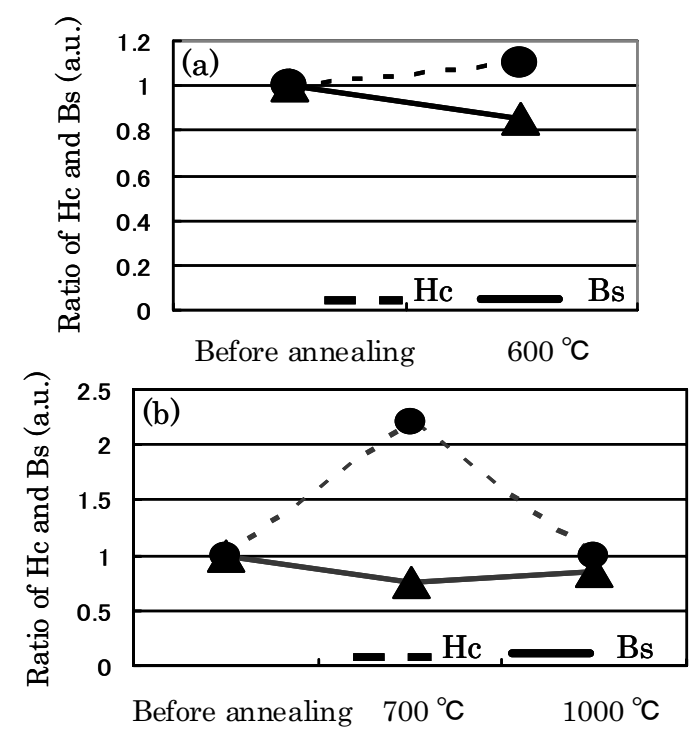

Fig. 4 Ratio of $\mathrm{Hc}$ and Bs

(a) $\mathrm{Fe}-\mathrm{Ni}$,(b) $\mathrm{Fe}-\mathrm{Co}$ (before annealing).

Fig.4よりFe-Ni合金めっきは保磁力，飽和磁化ともに大きな 変化が見られなかったが, 後述する磁気センサによる評価では 信号強度の著しい増加が見られた．Fe-Co合金めっきでは

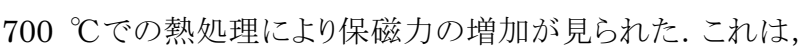
熱処理による結晶性の向上に起因しているものと考えられる.

\section{3. 微細構造の形成とスケール評価}

フォトリソグラフィーと電気めっきの組み合わせにより, 磁性体 の微細パターンを形成することを試みた. アスペクト比の高い 微細構造を形成するために, レジストには化学増幅型の厚膜 
フォトレジストを用いた. Table 1にフォトリソグラフィーの条件, Fig.5に今回行ったプロセスの概略図について示す.

このプロセスにより作製したパターン幅50 $\mu \mathrm{m}$, 高さ50 $\mu \mathrm{m}$, ピッチ200 $\mu \mathrm{m}$ の $\mathrm{Fe}-\mathrm{Ni}$ 合金による磁気スケールのSEM画像 をFig.6に示す. Fig.6より, Fe-Ni合金めつきにより目的のパタ ーンが形成されていることが確認できる. また, Ni, Fe-Ni合金, $\mathrm{Fe}-\mathrm{Co}$ 合金いずれのめっきで作製したパターンともレジスト剥 離工程やセンシングの際の摩擦に耐えられる十分な強度を持 っており, 熱処理の際にも剥離や変形などの問題は発生しな かった。

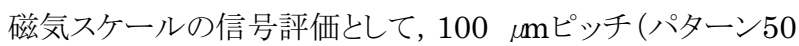
$\mu \mathrm{m} /$ 間隔50 $\mu \mathrm{m}$ ) でスケールを作製し, MRセンサーおよび 測定ステージを用いて評価を行った. 評価装置およびセンサ

Table 1 Photolithography processes.

\begin{tabular}{|c|c|c|}
\hline \multicolumn{2}{|l|}{ Photoresist } & SU-8 \\
\hline \multicolumn{2}{|l|}{ Pretreatment } & Acetone \\
\hline \multicolumn{2}{|l|}{ Coating } & Applicator \\
\hline \multirow{2}{*}{ Pre-baking } & $73^{\circ} \mathrm{C}$ & $450 \mathrm{sec}$ \\
\hline & $103^{\circ} \mathrm{C}$ & $600 \mathrm{sec}$ \\
\hline \multicolumn{2}{|l|}{ Exposure } & $300 \mathrm{mj} / \mathrm{cm}^{2}$ \\
\hline \multirow{2}{*}{ Post exposure baking } & $73^{\circ} \mathrm{C}$ & $330 \mathrm{sec}$ \\
\hline & $103^{\circ} \mathrm{C}$ & $540 \mathrm{sec}$ \\
\hline \multicolumn{2}{|l|}{ Development } & $300 \mathrm{sec}$ \\
\hline \multicolumn{2}{|l|}{ Rinsing } & IPA $60 \mathrm{sec}$ \\
\hline
\end{tabular}

(1) Substrate

(2) Resist coating

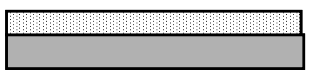

(3) Exposure

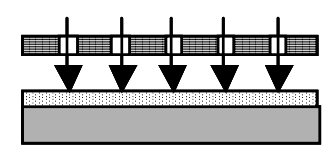

(4) Development

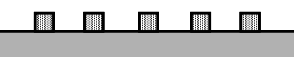

(5) Masking

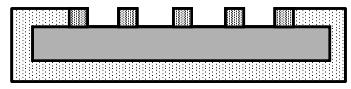

(6) Electro-plating

(7) Resist removal
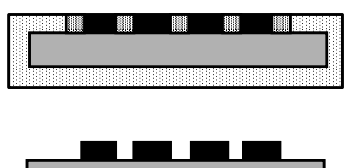

Fig. 5 Schematics for photolithograph and electroplating process.
一の構造の概略をFig.7に示す. MRセンサーは基板垂直方 向に感度を持つよう，幅45 $\mu \mathrm{m}$ の InSb薄膜を $150 \mu \mathrm{m}$ 間隔で 平行に 2 本配置し, これらを直列に接続した構造とした.

MRセンサーとスケールとのクリアランスは $150 \mu \mathrm{m} と し$, バイ アス磁石によるスケール直上の磁界の分布を 2 本のInSb薄膜 の抵抗の差として中点にかかる電圧の変化の形で検出した.

Fig.8に(a)Niめつき, (b)Fe-Ni合金めつき, (c)Fe-Ni合金め つき $\left(600{ }^{\circ} \mathrm{C}\right.$ で熱処理)，(d)Fe-Co合金めっきで作製したそれ ぞれ100 $\mu \mathrm{m}$ ピッチのスケール出力の結果を示す.

Fig.8より, 今回使用した素材の中ではFe- $\mathrm{Ni}$ 熱処理を施し たパターン (c)が最も信号強度が強く, 熱処理を行うことにより, 信号強度が約3倍に向上していることが確認できた.これは熱 処理による結晶化が影響しているものと考えられる.

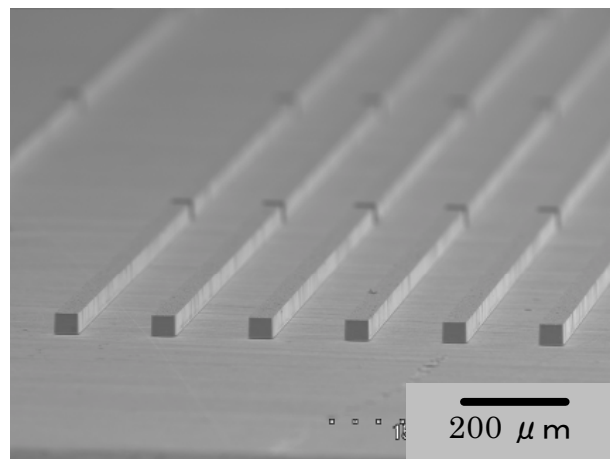

Fig. 6 Pitch $200 \mu \mathrm{m} \mathrm{Fe-Ni} \mathrm{pattern.}$ (pattern $50 \mu \mathrm{m} /$ space $150 \mu \mathrm{m} /$ height $50 \mu \mathrm{m}$ )

(a) MR sensor Oscilloscope

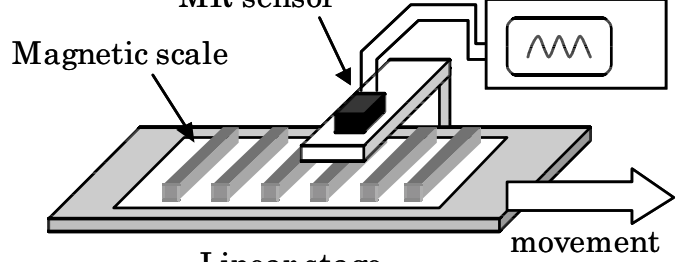
Linear stage

(b)

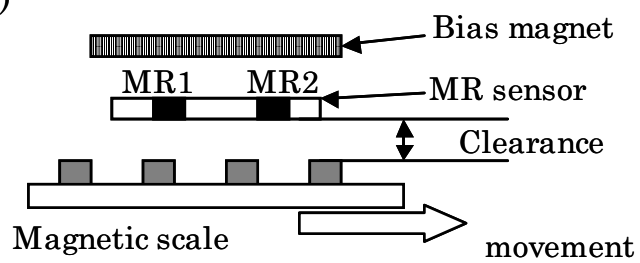

(c)

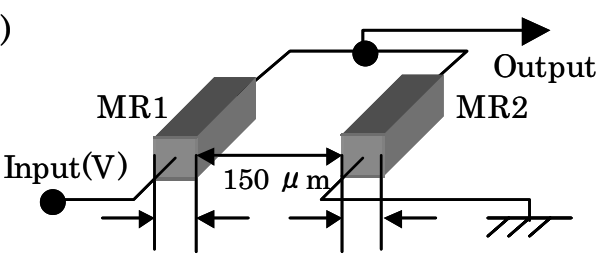

$45 \mu \mathrm{m}$

$45 \mu \mathrm{m}$

Fig. 7 Schematics for measurement equipment. (a) Overview, (b) sensor area magnification, and (c) sensor internal circuit 


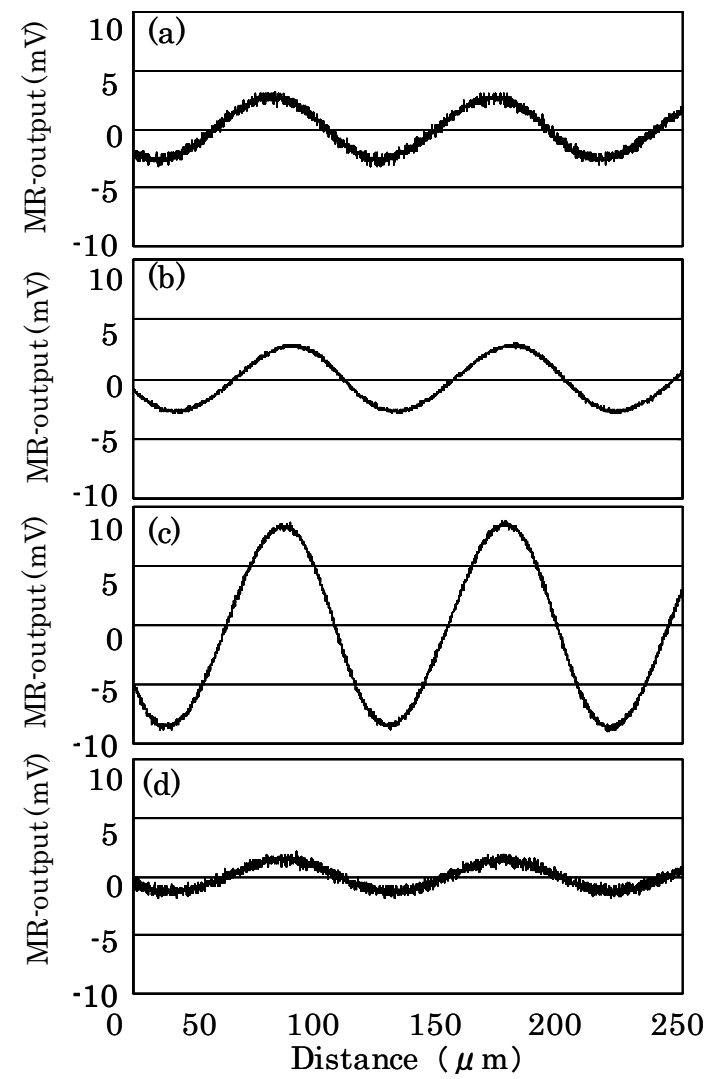

Fig. 8 Signals of MR sensors.

(a) $\mathrm{Ni},(\mathrm{b}) \mathrm{Fe}-\mathrm{Ni}$, (c) $\mathrm{Fe}-\mathrm{Ni}$ (annealed), and (d)Fe-Co

Fig.8(c)のスケールを用い, Fig.7(b)に示したクリアランスを 変化させた際のスケール出力の測定結果をFig.9に示す.

Fig.9より, スケールからの信号強度はセンサーとスケールと のクリアランスが $150 \mu \mathrm{m}$ まではほとんど変化しないが, それ 以上に広がると急激に減衰することが確認された。

\section{5. まとめ}

本研究では, 高分解能かつ耐熱・耐放射線性の高い磁気ス ケールの開発の可能性について, 紫外線フォトリソグラフィーと ニッケル等の磁性体金属のめつきを組み合わせて軟磁性体金 属の微細構造を形成し, MRセンサーとバイアス磁石の組み合 わせにより非接触で検出することを試みた. それにより以下の 知見を得た。

1) $\mathrm{Fe}-\mathrm{Ni}$ や $\mathrm{Fe}-\mathrm{Co}$ といった磁性体のめっきにより微細パターン を形成し, 単結晶InSb型MRセンサーにより非接触で検出す ることができ, 磁気スケールとして使用できることが確認できた. 2)MRセンサーによる測定では今回使用した素材の中で最も 透磁率の高いFe-Niから最も強い信号を得られた. また Fe-Ni は熱処理により大幅に信号強度を向上させることが出来,これ は熱処理による結晶性の向上に起因していると考えられる.

3)センサーとスケールとのクリアランスは150 $\mu \mathrm{m}$ までは信号 強度に大きな影響がないが, それ以上離れると急激に信号強 度が減衰することが確認された。

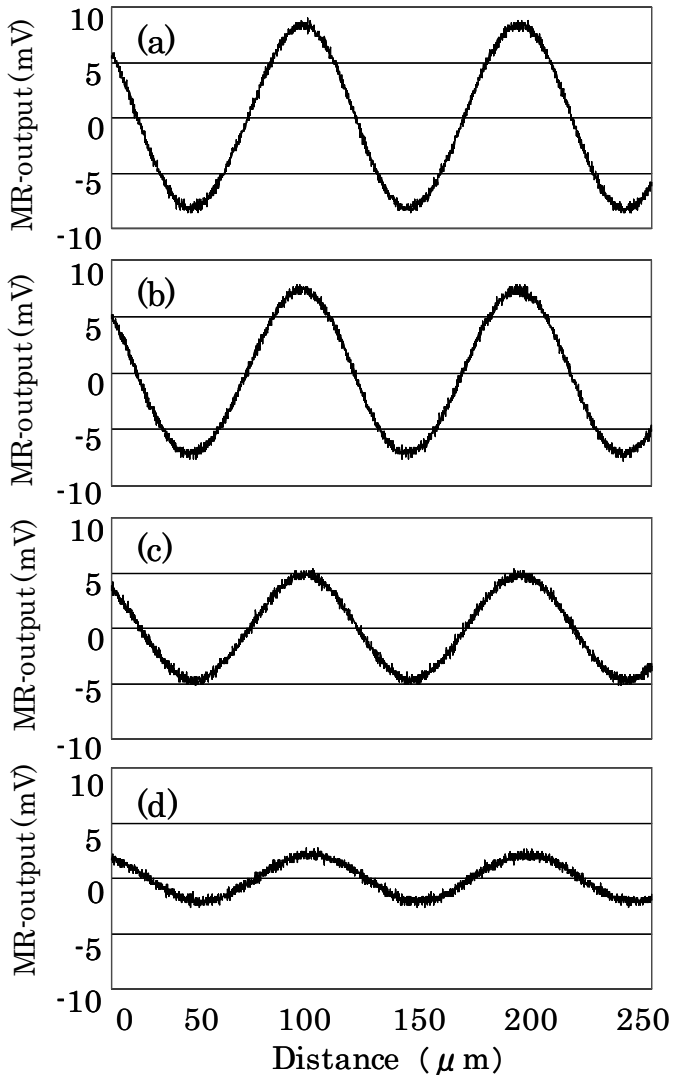

Fig. 9 Signals of MR sensor when distance between sensor and scale is increased.

(a) $140 \mu \mathrm{m}$, (b) $150 \mu \mathrm{m}$, (c) $175 \mu \mathrm{m}$, and (d) $200 \mu \mathrm{m}$

本論文で作製した磁気スケールは, 金属素材のみで形成さ れているため, プラスチックマグネットに比べ高温や放射線に 対して高い耐性を持っているであろうことが期待でき，高温や 放射線而性の評価などを行うことで, 実用化が可能であると考 えられる。

\section{Referrences}

1)T.Ohmori: Hukyuban Sensa Jituyou Binran (in Japanese), p.507 (FUJI.Technosystem,Tokyo,2000).

2)T.Seguchi,N.Hayakawa,K.Yoshida,N.Tamura, Y.Katsumura, and Y.Tabaka : Radiat. Phys. Chem.26,221(1985).

3)Kiyoshi.H : Koubunsizairyou no Jyumyo hyoka.Yosokuhou (in Japanese),P.31-36(IPC,Tokyo,1994).

4)P.Bley and J.Mohr:FED Journal Vol.5 Suppl.1,P.34-48(1994). 5)M.Yasui,Y.Hirabayasi, and H.Fujita : Journal of The Surface Finishing Society of Japan,55,P.226-231(2004)

6)Takeaki.F,Jyunzou.M : Electroplating \& Chemicalplating Guidebook (in Japanese),p.382(Tokyo mekki zairyou kyoudou kumiai,Tokyo,1987).

7)Hidehiko.E , Takashi.K : Goukinmekki (in Japanese) , p.152 (Nikkan Kougyo Shuppan,Tokyo,1987).

8)S.Glasstone,J.C.Speakman:J.Electrodepositors'tech.Soc., 8, 11 (1932).

2008年10月 20 日受理， 2009 年1月7日再受理， 2009 年 1 月 9 日採録 